\title{
God's silence
}

\author{
Elisa Paganini
}

Published online: 12 November 2010

(C) The Author(s) 2010. This article is published with open access at Springerlink.com

\begin{abstract}
Vagueness manifests itself (among other things) in our inability to find boundaries to the extension of vague predicates. A semantic theory of vagueness plans to justify this inability in terms of the vague semantic rules governing language and thought. According to a supporter of semantic theory, the inability to find such a boundary is not dependent on epistemic limits and an omniscient being like God would be equally unable. Williamson (Vagueness, 1994) argued that cooperative omniscient beings adequately instructed would find a precise boundary in a sorites series and that, for this reason, the semantic theory misses its target, while Hawthorne (Philosophical Studies 122:1-25, 2005) stood with the semantic theorists and argued that the linguistic behaviour of a cooperative omniscient being like God would clearly demonstrate that he does not find a precise boundary in the sorites series. I argue that Hawthorne's definition of God's cooperative behaviour cannot be accepted and that, contrary to what has been assumed by both Williamson and Hawthorne, an omniscient being like God cannot be a cooperative evaluator of a semantic theory of vagueness.
\end{abstract}

The title was suggested to me by Paolo Casalegno who discussed this paper with me on many occasions. I presented this work at different stages of its elaboration during the following events: 2006 SIFA Conference in Cesano Maderno, 2008 Conference 'Vagueness and Language Use' in Paris, 2008 Seminar on analytic philosophy in Bologna, 2008 Eidos Metaphysics Conference in Geneva, 2008 ECAP6 in Krakow and 2009 Joint Session of the Aristotelian Society and the Mind Association in Norwich. I would like to thank everyone who attended my presentations and raised objections or questions.

\section{E. Paganini}

Dipartimento di Filosofia, Università degli Studi di Milano,

Via Festa del Perdono, 7, 20122 Milano, Italy

E. Paganini $(\bowtie)$

Via Soncino, 3, 20123 Milano, Italy

e-mail: elisa.paganini@unimi.it 
Keywords Vagueness - Omniscience

Let us imagine a sorites series of women: the first woman is $2 \mathrm{~m}$ tall, the last is $1 \mathrm{~m}$ tall and there is a very small difference in height between each woman and the following one. Let us suppose moreover that all the women have a similar physical constitution. If any competent speaker were asked to individuate the last tall woman in the series, she would not be able to. Suppose now that a competent speaker is forced to answer the question 'Is this woman tall?' for each woman in the series starting from the woman who is $2 \mathrm{~m}$ tall and going on through all the series: she will answer 'yes' when confronted with the first woman but she will not go on answering 'yes' right to the end, she will stop saying 'yes' somewhere. Different people would stop saying 'yes' when confronted with different women in the series and if the same person is forced to do the experiment more than once, she may stop saying 'yes' when confronted with a different woman each time.

According to a semantic theory of vagueness, the inability to find a specific boundary in the sorites series does not depend on any ignorance on the part of a competent speaker. According to such a theory, vagueness depends on the rules that govern language and thought and it is because of these rules that the extension of vague predicates is without boundaries. The theory is committed to maintaining that even an omniscient being would be equally unable to individuate a specific boundary in any sorites series.

Now, the philosophical issue under consideration is the following: do the semantic theories of vagueness account for such a boundary-less extension of vague predicates? In order to test a semantic theory the following strategy has been adopted: suppose that, as any semantic theory holds, vagueness depends on the rules of language and thought only (and not on any ignorance on the part of human beings); consider then how an omniscient being would behave if asked, for each object in a sorites series, whether it possesses the vague property under consideration. For example, suppose that the omniscient being is confronted with the sorites series of women previously considered and the question 'Is this woman tall?' for each woman in the series: how would he behave?

Williamson (1994, pp. 198-201) argued that if an omniscient being were cooperative and conservative in the use of his discretion, he would stop answering 'yes' at a precise point in the sorites series, and any other omniscient being, who were equally cooperative and conservative in the use of his discretion, would stop answering 'yes' when confronting the same woman. So, according to Williamson, the semantic theory misses its target: contrary to what is supposed, there is a boundary in the sorites series known to any omniscient being.

Recently, Hawthorne (2005) argued in support of a semantic theory of vagueness, i.e. supervaluationism. The argument is intended to show that, if a cooperative omniscient being, i.e. God, were confronted with the experiment considered above, he would not stop saying 'yes' at any precise point in the sorites series. The reason is that Hawthorne's definition of God's cooperation is incompatible with any precise linguistic behaviour when confronting a sorites series. But what would be the 
behaviour of a cooperative God when confronted with the experiment in consideration? According to Hawthorne, a cooperative God would start saying 'yes' if asked 'Is this woman tall?' when confronted with the first woman in the series. Then, going on through the sorites series with the same question, God's linguistic performances of the word 'yes' would change gradually until he would definitely not say 'yes'. According to Hawthorne, in so far as there is no clear boundary in God's linguistic behaviour, this shows that he does not find any boundary in the sorites series because there is none to be found.

I will argue that Hawthorne's definition of God's cooperation cannot be accepted even by a supporter of supervaluationism and that, in general, an omniscient being like God cannot be cooperative if a semantic theory of vagueness like supervaluationism is correct. Contrary to what has been assumed by both Williamson and Hawthorne, I claim that an omniscient being like God cannot serve as an evaluator of a semantic theory. I proceed in the following way: I introduce some remarks about supervaluationism and higher-order vagueness (Sect. 1), I present Hawthorne's definition of God's cooperation and his justification for it (Sect. 2), I object to Hawthorne's argument in support of this definition (Sect. 3) and I argue that God cannot be cooperative in the experiment described, if a semantic theory of vagueness like supervaluationism is correct (Sect. 4). At the end, I add some remarks on the supervaluationist theory and the results presented (Sect. 5).

\section{Preliminary remarks}

A semantic theory copes with the boundary-less extension of vague predicates through borderline cases and higher-order vagueness. Let us consider how a specific semantic theory, i.e. supervaluationism, deals with it. As is well known, supervaluationism substitutes the notions of truth and falsity with those of supertruth and superfalsity. Moreover, supervaluationism rejects bivalence: there are supertrue utterances, there are superfalse utterances and there are utterances which are neither supertrue nor superfalse, these latter utterances fall into a truth-value gap. Now, reconsider the sorites series of women previously presented; according to supervaluationism there are women such that it is supertrue that they are tall and there are women such that it is superfalse that they are tall, but these women do not exhaust the sorites series otherwise there would be a boundary in the extension of the predicate 'tall'.

In order to manage this idea a little more precisely, it is useful to introduce the 'Definitely' operator which is governed, inter alia, by the following schema:

(D) If $u$ means $\mathrm{P}$, then $u$ is supertrue iff Definitely $\mathrm{P}$

Now, how can we say that there is no boundary between the definitely tall women and the definitely not tall woman? Unfortunately, there is nothing that can be said explicitly, but a consequence is that any utterance which expresses the proposition (1) cannot be supertrue (where 'Def' is an abbreviation for 'Definitely' and ' $T$ ' is the predicate 'tall'): 


\section{(1) $\exists \mathrm{x}\left(\operatorname{Def} \mathrm{Tx} \wedge \operatorname{Def} \neg \mathrm{Tx}^{\prime}\right)$}

It may be believed that any utterance of (1) is not supertrue because there are (firstorder) borderline cases: women such that they are neither definitely tall nor definitely not tall. Such borderline cases may of course occur, ${ }^{1}$ but it should not be believed that the definitely tall women, the definitely not tall women and the prospective neither definitely tall nor definitely not tall women exhaust the sorites series, otherwise there will be a boundary in the extension of the vague predicate, i.e. an utterance of (2) would be supertrue:

\section{(2) $\exists x\left(\right.$ Def Def Tx $\wedge$ Def $\neg$ Def Tx $\left.{ }^{\prime}\right)$}

But no utterance of (2) can be supertrue, because if it were, there would be a boundary in the sorites series. How can we say that there is no boundary between the definitely tall women and the not definitely tall women? There is nothing that can be said explicitly but a strict consequence of such an assumption is that any utterance of (2) cannot be supertrue. It may be believed that no utterance of (2) is supertrue because there are second-order borderline cases: women such that they are neither definitely definitely tall nor definitely not definitely tall. Such second-order borderline cases may of course occur, ${ }^{2}$ but it should not be believed that the definitely tall women, the definitely not tall women, the prospective first-order and second-order borderline cases exhaust the sorites series. Otherwise an utterance of (3) will be supertrue:

\section{(3) $\exists x\left(\right.$ Def Def Def Tx $\wedge$ Def $\neg$ Def Def $\left.\operatorname{Tx}^{\prime}\right)$}

But an utterance of (3) cannot be supertrue, otherwise there would be a boundary in the sorites series. The same reasoning previously presented can be repeated ad infinitum. There is no proposition (or set of propositions) to express the fact that there is no boundary between the definitely tall women and the others, but an important consequence of such an assumption is that no utterance which expresses one of the infinite propositions reflecting the following schema is supertrue ${ }^{3}$ :

$$
\text { (E) } \exists x\left(\operatorname{Def} \operatorname{Def}^{n} T x \wedge \operatorname{Def} \neg \operatorname{Def}^{n} \operatorname{Tx}^{\prime}\right)
$$

with $0 \leq \mathrm{n} \leq \infty$ (where $\mathrm{n}$ is the number of the iterations of Def to which it is applied). ${ }^{4}$

\footnotetext{
${ }^{1}$ And they may of course not occur.

2 And they may of course not occur.

${ }^{3}$ As is well known, higher-order vagueness does not imply that all the utterances of (E) are superfalse. This is an important consequence of an argument presented by Graff Fara (2003). For this reason, it is assumed here that none of the utterances of (E) is supertrue, without assuming that all of them are superfalse.

${ }^{4} \mathrm{I}$ am not assuming that schema (E) exhausts the set of utterances which are not supertrue if boundaryless between the definitely tall women and the rest is granted. As a matter of fact, neither should the infinite set of propositions be characterized by the following schema: $\exists x\left(\operatorname{Def}^{n}{ }^{n} x \wedge \neg \operatorname{Def}^{n} T^{\prime}\right.$ ) with $1 \leq \mathrm{n} \leq \infty$, be assumed to be supertrue. I am indebted to an anonymous referee for helping me to be explicit on this point.
} 
It can be questioned whether a semantic theory like supervaluationism, even allowing for the non-supertruth of any existential (E), is still committed to some boundary in the sorites series. ${ }^{5}$ We can reason as follows: the definitely operator 'Def' was introduced in order to account in the object language for the vagueness of the semantic notion of supertruth. In order to explain the use of the Definitely operator a semantic device has to be introduced; usually, the Definitely operator is analysed as a modal operator and the semantics are structured by appealing to the notion of admissible specification. Let us suppose that an appropriate operator is introduced in the object language-let us call it $\Psi$ - which accounts in the object language for the semantic devices adopted for describing the use of the Definitely operator; an interesting question is the following: is there a supertrue existential $\left(\mathrm{E}^{*}\right)$ ?

$$
\left(\mathrm{E}^{*}\right) \exists \mathrm{x}\left(\operatorname{Def} \Psi \mathrm{Tx} \wedge \operatorname{Def} \neg \Psi \mathrm{Tx}^{\prime}\right)
$$

It is evident that if an existential $\left(\mathrm{E}^{*}\right)$ were supertrue, the semantic theory would miss its target: in such a case the semantic theory would be committed to a boundary in the sorites series and the test with the omniscient being would be superfluous.

But a semantic theory should maintain that any existential $\left(\mathrm{E}^{*}\right)$ is not supertrue. The explanation to be given depends on a parallel between the semantic devices adopted for explaining the use of a vague language without the Definitely operator and the semantic devices used to explain the vagueness of the Definitely operator. In order to explain the vagueness of a language without the Definitely operator, the semantic device of supertruth is introduced (such a device is itself explained in terms of precisifications of the vague words). This semantic device allows for the existential (E-) to be supertrue without being committed to any precise boundary in the sorites series.

$$
(\mathrm{E}-) \exists \mathrm{x}\left(\mathrm{Tx} \wedge \neg \mathrm{Tx}^{\prime}\right)
$$

An obvious objection to such a claim is the following: even if there is not a precise boundary in the sorites series between the tall women and the not tall women, there is a boundary between the women such that it is supertrue that they are tall and all the others.

Such an objection is notoriously answered in the following way: the notion of supertruth is itself vague and in order to account for such vagueness the Definitely operator is introduced. The use of the latter is explained through modal semantics together with the notion of admissible specification, and it can be objected that it is in principle possible to introduce some $\Psi$ operator which accounts for the semantic devices used in order to describe the use of the Definitely operator and which allows for an utterance expressing $\left(\mathrm{E}^{*}\right)$ to be supertrue.

The answer to such an objection parallels the one previously considered: whatever the semantic device introduced in order to account for the Definitely operator is, it should itself be vague and, as a consequence, any $\Psi$ should be vague; as any other

\footnotetext{
${ }^{5}$ The following is my construal of an objection raised by Timothy Williamson. I'd like to thank him for his useful observations.
} 
operator $\Xi$ adopted in order to describe the semantics of $\Psi$ should be vague, as well as any operator $\Omega$ adopted in order to describe the semantics of $\Xi$, and so on ad infinitum.

For these reasons, one consequence of the boundary-less extension of vague predicates is that there is not any supertrue existential either of the form $(E)$ or of the form $\left(\mathrm{E}^{*}\right)$. And it is exactly under such assumptions that the actual behaviour of a cooperative omniscient being would be interesting if it were possible.

For simplicity, I will limit my account to the assumption that the language under consideration contains the Definitely operator and that it is a consequence of the boundary-less extension of vague predicates that none of the existentials (E) is supertrue, without being all superfalse. ${ }^{6}$ I assume that my argument would not undergo any significant changes if other meta-linguistic operators were introduced in the object language.

\section{Hawthorne and God's cooperation}

Suppose that God is confronted with the experiment described at the beginning (i.e. the sorites series of women and the question 'Is this woman tall?' for each woman in the series). According to Hawthorne, if God is cooperative he should conform to the following rule (which Hawthorne calls 'Tracking'):

(H) Def (God says 'Yes' iff the woman under consideration is tall)

In order to argue this, Hawthorne ${ }^{7}$ assumes the two following premisses:

A] [God says 'Yes' and $\neg$ (the woman under consideration is tall)] $\rightarrow \neg($ God is cooperative)

B] [ $\neg$ (God says 'Yes') and the woman under consideration is tall $] \rightarrow \neg$ (God is cooperative)

From these two premisses, by contraposition and logical equivalence it follows that:

C] God is cooperative $\rightarrow$ [God says 'Yes' iff the woman under consideration is tall] Assuming that:

D] God is cooperative

from $\mathrm{C}]$ and $\mathrm{D}]$, it follows by modus ponens that:

E] God says 'Yes' iff the woman under consideration is tall

And if E] is accepted by an omniscient being, it means, according to Hawthorne, that 'Tracking' is in force, i.e.:

(H) Def (God says 'Yes' iff the woman under consideration is tall)

\footnotetext{
6 As I wrote in footnote 2, this is a consequence of an argument presented by Graff Fara (2003).

${ }^{7}$ Hawthorne (2005, p. 19), the sorites series considered by Hawthorne is different from the one taken into account here.
} 


\section{My objection to Hawthorne}

My objection to Hawthorne is that a cooperative omniscient being should not be guided by 'Tracking' (i.e. (H)). And I believe that this should be recognized even by a supporter of supervaluationism sympathetic to Hawthorne's definition of omniscience.

Let us first consider the definition of omniscience Hawthorne proposes, i. e.:

(O) $\forall \mathrm{x}$ ( $\mathrm{x}$ is omniscient iff $\forall \mathrm{P}((\mathrm{x}$ knows $\mathrm{P}$ iff $\mathrm{x}$ believes $\mathrm{P})$ and ( $\mathrm{x}$ believes $\mathrm{P}$ iff Def P)) $)^{8}$

From my point of view, the most significant consequence of this definition is that if a proposition has a definite higher-order of vagueness, then the omniscient being believes and knows that it has that specific higher-order of vagueness. For example, assuming Hawthorne's definition of omniscience, that God is omniscient and that Q is first-order vague, it follows that God believes and knows that $\mathrm{Q}$ is first order vague. This point can be made a little more rigorous as follows:

\begin{tabular}{|c|c|c|c|}
\hline 1 & $\begin{array}{l}\forall \mathrm{x}(\mathrm{x} \text { is omniscient iff } \forall \mathrm{P}((\mathrm{x} \text { knows } \mathrm{P} \text { iff } \mathrm{x} \text { believes } \mathrm{P}) \\
\quad \text { and }(\mathrm{x} \text { believes } \mathrm{P} \text { iff } \operatorname{Def} \mathrm{P})))\end{array}$ & & Ass. \\
\hline 2 & God is omniscient & & Ass. \\
\hline 3 & Def $(\neg$ Def Q and $\urcorner$ Def $\urcorner Q)$ & & Ass. \\
\hline 4 & $\begin{array}{l}\text { God is omniscient iff } \forall \mathrm{P}((\text { God knows } \mathrm{P} \text { iff God believes } \mathrm{P}) \\
\quad \text { and }(\text { God believes } \mathrm{P} \text { iff Def } \mathrm{P})))\end{array}$ & 1 & $\forall \mathrm{E}-1$ \\
\hline 5 & $\forall \mathrm{P}(($ God knows $\mathrm{P}$ iff God believes $\mathrm{P})$ and (God believes $\mathrm{P}$ iff Def $\mathrm{P}))$ & 1,2 & $\mathrm{MP}-2,4$ \\
\hline 6 & 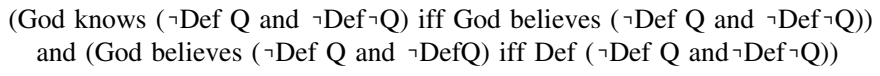 & 1,2 & $\forall \mathrm{E}-5$ \\
\hline 7 & (God believes ( $\urcorner$ Def $Q$ and $\urcorner$ Def $\urcorner Q)$ iff Def $(\neg$ Def Q and $\urcorner$ Def $\urcorner Q))$ & 1,2 & $\wedge \mathrm{E}-6$ \\
\hline 8 & God believes ( $\urcorner$ Def $Q$ and $\urcorner$ Def $\urcorner Q$ ) & $1,2,3$ & $\mathrm{MP}-3,7$ \\
\hline & (God knows ( $\urcorner$ Def $Q$ and $\neg$ Def $\urcorner Q)$ iff God believes ( $\urcorner$ Def Q and $\urcorner$ Def $\urcorner Q)$ ) & 1,2 & $\wedge \mathrm{E}-6$ \\
\hline & God knows ( $\neg$ Def $Q$ and $\neg$ Def $\urcorner Q$ ) & $1,2,3$ & $\mathrm{MP}-8,9$ \\
\hline
\end{tabular}

Now, given this definition of omniscience, I argue that there is a case in which both premise B] and the conclusion E] of Hawthorne's argument are not supertrue. Let us consider the following situation: Annie is a case of first-order vagueness for tallness (i.e. it is supertrue that it is neither supertrue nor superfalse that Annie is tall). By Hawthorne's definition of omniscience, it follows that God believes (and knows) that Annie is a case of first-order vagueness for tallness. ${ }^{9}$ Let us now suppose that God is asked 'Is Annie tall?'. What would God answer if he were cooperative? I suppose that the best he can do is to say what he actually believes

\footnotetext{
8 According to this definition, omniscience is uniquely defined by propositional attitudes. However, according to a semantic theory of vagueness, vagueness depends on the rules which govern language and thought. If the latter definition is accepted, an omniscient being should be expected to know the metalinguistic rules which govern language and thought. The assumption that an omniscient being should be able to manage meta-linguistic rules will be taken for granted in Sect. 4.

9 This point is more evident if it is supposed that the proposition expressed by 'Annie is tall' is Q in the argument I have just presented.
} 
about Annie's tallness and is supertrue about it; this would make him maximally informative. A cooperative God should be expected to say something like 'it is neither supertrue nor superfalse' or 'it is indeterminate' or 'she is a case of first-order vagueness for tallness'. Now, if that is what a cooperative God says, then he will say something definitely different both from 'yes' and from an indefinite performance of the word 'yes'.

In the case of God's confronting Annie, the following is the case:

'the woman under consideration is tall' is neither supertrue nor superfalse

"God says 'Yes'" is superfalse

'God is cooperative' is supertrue

In such a case, both

B] [ $\neg($ God says 'Yes') and the woman under consideration is tall $] \rightarrow \neg$ (God is cooperative)

and

E] God says 'Yes' iff the woman under consideration is tall

are neither supertrue nor superfalse.

\section{The impossibility for God to cooperate}

If Hawthorne's definition of God's cooperation cannot be adopted, how should God's cooperative behaviour be defined? In the case of God confronting Annie, I assumed that God says what he knows concerning Annie's tallness and it is supertrue. Extending this same idea, God's cooperation may be defined in the following way: whenever it is definitely the case that the woman under consideration is tall, God answers 'yes' to the question 'Is this woman tall?'; and whenever God answers 'yes', it should be inferred that it is definitely the case that the woman under consideration is tall. Whenever the woman under consideration is a borderline case of any of the infinite higher-orders, God says that she is a borderline case of that specific higher-order of vagueness; and whenever God says that the woman under consideration is a borderline case of a specific higher-order of vagueness, it is possible to infer that what he says is supertrue.

The idea can be expressed more formally through this set of meta-linguistic rules (let us call them (C), where ' $Q$ ' is 'the woman under consideration is tall':

$$
\text { (c) }\left\{\begin{array}{l}
\mathrm{Q} \dashv \vdash \text { God says 'yes' } \\
\text { For all } \mathrm{n}, 0 \leq \mathrm{n} \leq \infty \\
\neg \text { Def } \operatorname{Def}^{\mathrm{n}} \mathrm{Q} \text { and } \neg \operatorname{Def} \rightarrow \operatorname{Def}^{\mathrm{n}} \mathrm{Q} \dashv \vdash \text { God says ' } \neg \operatorname{Def}_{\operatorname{Def}}{ }^{\mathrm{n}} \mathrm{Q} \text { and } \neg \operatorname{Def} \rightarrow \operatorname{Def}^{\mathrm{n}} \mathrm{Q} \text { ' }
\end{array}\right.
$$

But this infinite set of rules cannot characterize God's cooperation through the experiment under consideration. This is easy to grasp if we take into account a specific case, let us say the case of Mary. Mary is such that the utterance 'Mary is tall' cannot be characterized as supertrue, cannot be characterized as superfalse, and 
cannot be characterized as a case of any definite (finite or infinite) higher-order of vagueness. Whatever is said concerning the utterance 'Mary is tall' cannot be supertrue (except for tautologies). For this reason, the infinite set of rules in (C) cannot characterize God's behaviour when confronting Mary.

At first, Mary may appear an anomalous case. But this is not correct since a case like Mary is present in the sorites series under consideration. If there were not a case like Mary and any woman in the sorites series were definitely tall or definitely not tall or a definite borderline case of a specific (finite or infinite) higher order of vagueness, then at least one of the infinite existential utterances $(E)^{10}$ would be supertrue and there would be a boundary in the sorites series. But as long as it is a consequence of the boundary-less extension of vague predicates that none of the existentials (E) is supertrue, it follows that a case like Mary should be present in the sorites series.

Once the case of Mary is recognized to be highly relevant and inevitable in the sorites series, let us ask: how should God's cooperation be defined when confronting a case like Mary? We would like to supplement (C) with a rule like: 'when God is confronted with a case like Mary, he keeps silent; and when God keeps silent, it can be inferred that he is confronted with a case like Mary', but this is not a rule we can introduce if supervaluationism is adopted. In order to introduce such a rule, we should be able to fill the gap in the following meta-linguistic schema:

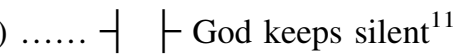

But there is nothing supertrue which can be said in order to characterize Mary's case; so, there is nothing which can be put in the instruction in order for God to be cooperative in a case like that of Mary. And, if there is no way to characterize God's cooperation concerning a case like Mary, there is no form of cooperative behaviour which can be adopted by God in such a case.

If God cannot be cooperative when confronting a case like Mary, it should be acknowledged that God cannot be cooperative when confronting the entire sorites series. The situation can be summed up as follows: God is confronted with a certain number of cases in a sorites series; for some of them there is apparently an instruction which regulates his cooperative behaviour, but for others there is no instruction, and as long as God may be cooperative in some cases but not in others, this is equivalent to not being cooperative in all cases.

In any sorites series there are cases (like the one of Mary) which do not allow for there being instructions regulating the cooperative behaviour of God and, as a consequence, God cannot be cooperative when confronting any sorites series. And if God cannot be cooperative, God is not a good test for a semantic theory of vagueness like supervaluationism.

\footnotetext{
10 See Sect. 1.

11 Another way to express the same idea (in Williamson-style terms) is the following. We would like to supplement (C) with a rule like: "When God is confronted with a case which allows for discretionality, he keeps silent; and whenever God keeps silent, it should be inferred that he is confronted with a case which allows for discretionality", but this is not a rule we may introduce if supervaluationism is adopted. In order to add such an instruction we should be able to characterize what it means for a case to allow for discretionality (i.e. we should be able to fill in the gap in (S)).
} 


\section{Supervaluationism and inexpressibility}

Let me sum up what I have done so far. As I wrote at the beginning of my paper, a semantic theory like supervaluationism assumes that the boundaryless extension of a vague predicate like 'tall' does not depend on ignorance; even an omniscient being like God would not be able to find a boundary in a sorites series. It is to challenge this assumption that Williamson introduced the mental experiment of forcing a pool of cooperative omniscient beings to find a precise boundary in a sorites series. And it is to defend this assumption that Hawthorne presented his definition of God's cooperation. I argued that an omniscient being like God cannot be cooperative if a semantic theory like supervaluationism is correct. My point is simply that a test such as that introduced by Williamson and developed differently by Hawthorne is not available.

A naïve question about my argument is the following: is this result to be considered in favour or against supervaluationism? My answer is 'neither'. As long as God cannot be cooperative, his behaviour cannot be either in support of or against the theory. ${ }^{12}$ My argument is a contribution to the methodology to be adopted in order to argue in favour of or against a semantic theory like supervaluationism.

A more profound question might be: what are the supervaluationist's commitments if my argument is correct? ${ }^{13}$ In my opinion, a supervaluationist should be ready to confront some kind of inexpressibility. Let me try to say something about this.

My argument shows that God cannot be cooperative because there is no complete definition of God's cooperation. In other words, God cannot be cooperative because there is no way to characterize his cooperative behaviour either linguistically or meta-linguistically when confronting a sorites series.

But why is his cooperative behaviour inexpressible? Because a case like Mary is inevitably included in any sorites series. And a case like Mary is precisely a case such that it is not supertrue, it is not superfalse and it is not a case of definite higherorder vagueness that the vague predicate under consideration applies to it. A case like Mary implies that a supertrue characterization of the utterance 'Mary is tall' is not available, i.e. there is not something which can be truly expressed (except tautologies) concerning that utterance.

But why is a case like Mary inevitable in any sorites series? Because of the boundaryless extension of vague predicates. And is boundaryless extension expressively definable? A positive definition of the boundaryless extension of vague predicates is actually not available. As far as I know, every attempt to give a positive definition of the boundaryless extension of vague predicates (the so called 'higher-order vagueness') has turned out to be incoherent. ${ }^{14}$ This result induced some philosophers to believe that the boundaryless extension of vague predicates is

\footnotetext{
${ }^{12}$ A supervaluationist may be disappointed by God's behaviour not being in support of her theory, but her disappointment is not a proof of any relevant thesis.

${ }^{13} \mathrm{I}$ am indebted to an anonymous referee for inducing me to give an answer to this question.

${ }^{14}$ It is worth mentioning Graff Fara (2003), Zardini (2006) and—for a metalinguistic definition—Varzi (2007)
} 
a myth to be abandoned. ${ }^{15}$ I believe instead that to reject higher-order vagueness means to abandon vagueness itself. Even if a supervaluationist does not have a positive definition of boundaryless extension of vague predicates, she can take into account important formal consequences of it which can be considered and analyzed. Among them, an interesting consequence is that none of the infinite utterances reflecting schema $(\mathrm{E})$ is supertrue, without all of them being superfalse.

Is this last assumption uncontroversial? Actually not. Whoever is acquainted with Zardini (2006) and Greenough (2003) can object that all existentials (E) are superfalse $^{16}$ which is paradoxical as Zardini demonstrates. ${ }^{17}$ As already stated, I assume on the contrary that some of them may be superfalse, but not all of them are superfalse.

The difference between Zardini and myself lies in the characterization of vagueness: while Zardini defines vagueness in terms of borderline cases, ${ }^{18} \mathrm{I}$ assume that vagueness is characterized by the boundaryless extension of vague predicates. This latter characterization has as a consequence that none of the existentials $(E)$ is supertrue, without committing to their all being superfalse; while Zardini's characterization has as a consequence that all existentials (E) are superfalse.

Now, I have to explain why I reject Zardini's definition of vagueness in terms of borderline cases. First of all, let me say that I do not exclude the presence of borderline cases: I suppose that whenever the Definitely operator is introduced, the borderline cases of any definite higher-order of vagueness are allowed. ${ }^{19}$ They are allowed, but they are not essential in order to characterize a sorites series. Suppose, for example, that a sorites series for the predicate 'tall woman' is constituted by definitely tall women, by women like Mary in Sect. 4 and by definitely not tall women: I believe that this is a sorites series appropriate for boundaryless extension of the vague predicate, but this sorites series does not present borderline cases of any definite higher-order (either finite or infinite). It is for this reason that I believe that a supervaluationist would reject the definition of vagueness in terms of borderline $\operatorname{cases}^{20}$ and for this reason she is not committed to the superfalsity of all existentials (E) and to the paradox Zardini presents.

If a supervaluationist is content with some consequences of the boundaryless extension of vague predicates without demanding an explicit definition of it, she will avoid incoherence. But this attitude has a cost: the supervaluationist does not have an explicit definition of the phenomenon of boundarylessness she claims to analyze.

\footnotetext{
15 This is actually the conclusion suggested by the philosophers mentioned in the previous footnote.

${ }^{16} \mathrm{I}$ am indebted to an anonymous referee for pointing out this objection to me. I will outline my general strategy against this objection, a more thorough discussion would require a separate paper.

17 The paradox derived from assuming all existentials (E) superfalse can also be found in Graff Fara (2003). Zardini (2006) uses different logical rules from Graff Fara (2003). They also have different philosophical attitudes towards that conclusion.

18 See (B) on p. 420 in Zardini (2006).

19 I consider the case of Annie in Sect. 3 because I believe that borderline cases of definite higher-order may be the case.

20 i.e. (B) in Zardini (2006).
} 
Open Access This article is distributed under the terms of the Creative Commons Attribution Noncommercial License which permits any noncommercial use, distribution, and reproduction in any medium, provided the original author(s) and source are credited.

\section{References}

Graff Fara, D. (2003). Gap principles, penumbral consequence, and infinitely higher-order vagueness. In J. C. Beall (Ed.), Liars and heaps (pp. 195-221). Oxford: Clarendon Press.

Greenough, P. (2003). Vagueness: A minimal theory. Mind, 112, 235-281.

Hawthorne, J. (2005). Vagueness and the mind of god. Philosophical Studies, 122, 1-25.

Varzi, A. (2007). Supervaluationism and its logics. Mind, 116, 633-676.

Williamson, T. (1994). Vagueness. London: Routledge.

Zardini, E. (2006). Squeezing and stretching: How vagueness can outrun borderlineness. Proceedings of the Aristotelian Society, 106.3, 419-426. 